\title{
A STUDY OF BRANCHING PATTERN OF RIGHT CORONARY ARTERY IN HUMAN HEARTS BY CORROSIVE CAST METHOD
}

Sneha. V. Kumar ${ }^{1}$, Bhavanaben K. Damor *2.

${ }^{1}$ M.S.(Anatomy), Associate Professor, Department of Anatomy, B. J. Medical College, Ahmedabad, Gujarat, India

${ }^{* 2}$ M.D.(Anatomy) Tutor, Department of Anatomy, Baroda medical college,Vadodara, Gujarat, India.

\section{ABSTRACT}

Background: Among heart diseases, coronary artery disease is one of the major causes of death in developing countries. Coronary circulation studied by various methods has demonstrated that there is a huge spectrum of variation in the branching pattern of the coronary arteries. Blood supply of the heart is achieved by two coronary arteries originating from the ascending aorta. In present study we prepare casts of coronary arteries by using corrosive cast technique to study the origin, course, termination and branching pattern of right coronary artery with its variations in human hearts.

Materials and Methods: 30 fresh specimens of human hearts which were obtained from the post-mortem room, B.J.Medical College, Ahmedabad. The cannula with cone shaped tip was introduced into both the coronary arteries through the coronary ostia. The lumen was cleaned and after that prepared resin was instilled in coronary ostia. After 24 hours the heart specimen was immersed in concentrated HCL. 30 casts of coronary arteries were prepared and observed.

Results: In All the specimens the right coronary artery ostium was present in the right anterior aortic sinus. Termination of RCA was found at the crux and beyond crux in 21 specimens (70\%); at the right border in 3 specimens $(10 \%)$ and at the left border in 5 specimens (16.66 \%). right marginal artery terminated at the apex in 23 specimens (76.66 \%) and near to the apex in 7 specimens (23.33\%). The PIVA arose from the RCA in 27 specimens ( $90 \%$ ) and from the LCA in 3 specimens (10\%). In 25 specimens ( $83.33 \%$ ). the sinu-atrial nodal artery was found to be originating from RCA and in 5 specimens $(16.66 \%)$ it originated from the LCA

Discussion: Anatomical variations of the coronary arteries are important, as decisions with regard to revascularization procedures in many cardiovascular diseases depend on knowledge of the anatomy of each individual artery. Knowledge of the normal and variation in branching pattern of right coronary artery is helpful to anatomist, radiologist and cardiologist as this is important for the interpretation of coronary angiography, various shunt surgery and stenting procedures.

KEY WORD: Right Marginal Artery, Posterior interventricular Artery, Sinu-atrial Nodal Artery, Corrosive Cast.

Corresponding Author: Dr. Bhavanaben K. Damor, Tutor, Department of Anatomy, Baroda medical college, S.S.G. Hospital, Vadodara- 390001, Gujarat, India, Phone no.: 09427659116, 09727072214 E-Mail: damorbhavana8@gmail.com

Access this Article online

Quick Response code

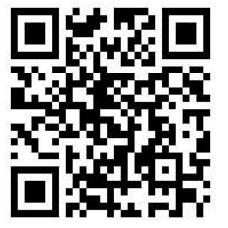

DOI: $10.16965 /$ ijar.2019.354

Journal Information

\section{International Journal of Anatomy and Research}

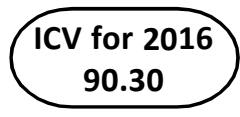

ISSN (E) 2321-4287 | ISSN (P) 2321-8967

https://www.ijmhr.org/ijar.htm

DOI-Prefix: https://dx.doi.org/10.16965/ijar

\section{(cc) $\mathrm{B} \%-\mathrm{NB}-\mathrm{BH}$}

\section{Article Information}

Received: 26 Nov 2019

Peer Review: 26 Nov 2019

Revised: 30 Dec 2019
Accepted: 05 Jan 2020

Published (O): 05 Feb 2020

Published (P): 05 Feb 2020

\section{INTRODUCTION}

In man the arterial supply to the heart is achieved by two coronary arteries which are the branches of the ascending aorta. In each case these arteries branch in such a manner that they occupy the atrio-ventricular and interventricular sulci in the shape of a crown. Hence they are called the coronary arteries. This basic 
arrangement has been recognized since the time of Vesalius. Similarly, anomalous arrangements have also been recognized since 1716 when Thebesius reported case of a single coronary artery [1].

Coronary predominance in man is determined by the artery that emits the posterior interventricular branch. Thus, dominance can be right, left or balanced circulation.

Knowledge of the normal and variant anatomy and anomalies of coronary circulation is an increasingly vital component in the management of congenital and acquired heart diseases [2].

The number of branches, their location and the myocardial mass irrigated are factors that determine the choice of therapy in all coronary artery bypass grafting (CABG) surgeries; thus surgery is preceded by a detailed analysis using angiographies.1 The increasing use of diagnostic and therapeutic interventional procedures make it essential to know the basic knowledge and detail of the coronary artery pattern [2].

The knowledge of the course and ramifications of blood vessels was based for a long time on the dissection of non-injected vascular systems. Only large vessels could therefore be described, for the small branches were usually cut off during the dissection [3]. Galen recommended introducing a wooden probe into the vessels during the dissection. But probes could not be introduced into very small vessels and they were not flexible. So he compromised to find the full course and relationships of the vascular system. Medical students studying human gross anatomy often have difficulty in understanding the three-dimensional structure of organs and the pattern of distribution of blood vessels by dissections method. Organ casting can make a significant contribution to medical education being an affordable and easy technique for visualizing anatomical specimens [4].

That is why it became necessary to develop vascular injection procedure like corrosive cast technique.

\section{AIMS AND OBJECTIVES:}

1) To study the origin, course, branching pattern and termination of right coronary arteries.
2) To find the dominance of coronary circulation.

3) To establish method of permanent preservation showing branching pattern of coronary arteries by corrosive cast method.

In present study an attempt has been made to prepare casts of coronary arteries by using corrosive cast technique to study the origin, course and branching pattern of coronary arteries with their variations in human hearts.

\section{MATERIALS AND METHODS}

To get the casts of coronary arteries- injection corrosion cast technique was used. In present study 30 fresh specimens of human hearts of which were obtained from the post-mortem room, of the forensic department, B. J. Medical College, Ahmedabad, gujarat during the period of 2 Years after taking permission of medical superintendent, civil hospital, Ahmedabad. The specimens were collected with a sufficient length of ascending aorta to facilitate cannulation and injection.

Each specimen was thoroughly washed to clean the blood clots. The cannula with cone shaped tip was introduced into both the coronary arteries through the coronary ostia one after the other. The lumen was cleaned using tap water and hydrogen peroxide. Solution was prepared by using epoxy resin and epoxy hardener.

Using a 20ml disposable syringe, prepared resin was instilled slowly and carefully with light, constant pressure to uniformly fill the coronary arteries. (Fig. 1) The procedure was continued until résistance was felt while injecting. At the end, little resin solution is put into the aorta to maintain the continuity of the arteries. After 24 hours the heart specimen was immersed in concentrated hydrochloric acid until all the heart tissue had been corroded. Then the cast was washed using tap water, dried and photographed to study.

\section{OBSERVATION}

The branches of coronary arteries were observed to study origin, course, branching pattern and termination of coronary arteries. (Fig.2)

In the present study All the specimens showed two coronary arteries emerging from the aortic sinuses. The right coronary artery ostium was 
present in the right anterior aortic sinus and the left coronary artery ostium was found in the left posterior aortic sinus in all the specimens. Neither accessory coronary ostium nor absence of any coronary ostium was observed.

Termination of right coronary artery was found at the crux and beyond crux in 21 specimens ( $70 \%$ ) as shown in Fig. 3 ; at the right border in 3 specimens (10\%) and at the left border after traversing entire atrio-ventricular groove in 5 specimens (16.66 \%). Only in 1 specimens right coronary artery terminated between right border and crux.

Observation on the level of termination of right marginal artery revealed that it terminated at the apex in 23 specimens (76.66 \%) (Fig. 4) and near to the apex in 7 specimens (23.33\%).

The posterior interventricular artery arose from the right coronary artery in 27 specimens (90 \%)[Fig.3] and from the left coronary artery in 3 specimens (10\%).

In present study it was observed that in 25 specimens $(83.33 \%)$ the sinu-atrial nodal artery was found to be originating from right coronary artery and in 5 specimens (16.66\%) it originated from the left coronary artery.

Fig. 1: Procedure of injecting epoxy resin into the coronary ostium.

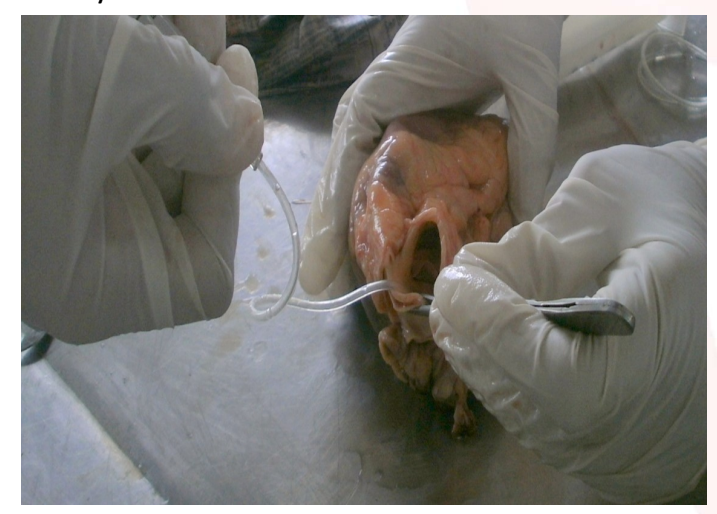

Table 1: Level of termination of right coronary artery.

\begin{tabular}{|c|c|c|c|c|}
\hline \multirow{5}{*}{ Right coronary artery } & \multicolumn{2}{|r|}{ Level of termination } & No. of specimens & Percentage (\%) \\
\hline & Normal & Crux or Beyond crux of heart & 21 & $70 \%$ \\
\hline & \multirow{3}{*}{ Variations } & At the right border & 3 & $10 \%$ \\
\hline & & Between right border and crux & 1 & $3.33 \%$ \\
\hline & & $\begin{array}{c}\text { At the left border } \\
\text { (After traversing entire AV groove) }\end{array}$ & 5 & $16.66 \%$ \\
\hline
\end{tabular}

\section{DISCUSSION}

The obtained values were compared with relevant studies done in past. In present study the right and left coronary ostia were present at
Fig. 2: Corrosive cast of coronary arteries.

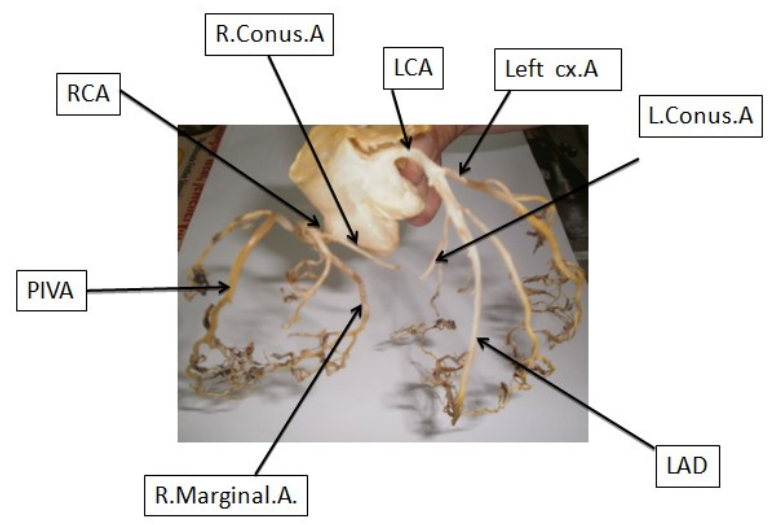

Fig. 3: Corrosive cast showing termination of RCA at crux or beyond crux of heart and Right dominance.

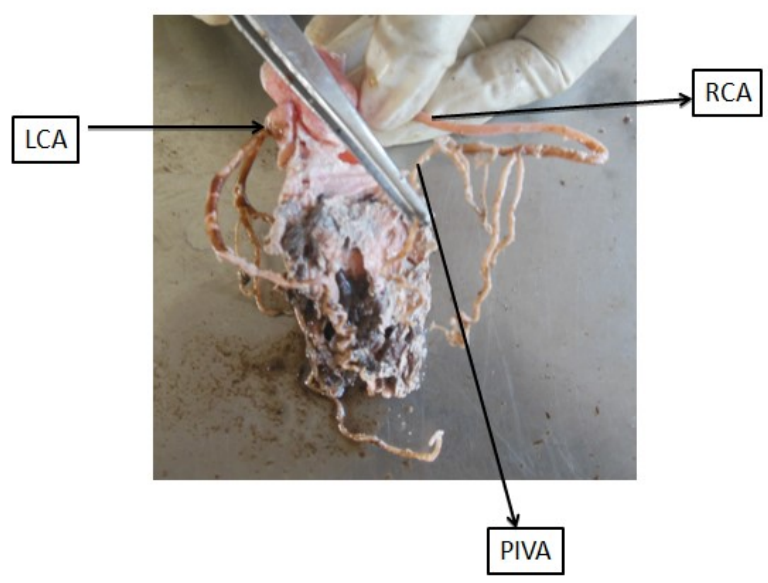

Fig. 4: Corrosive cast showing termination of right marginal artery at apex.

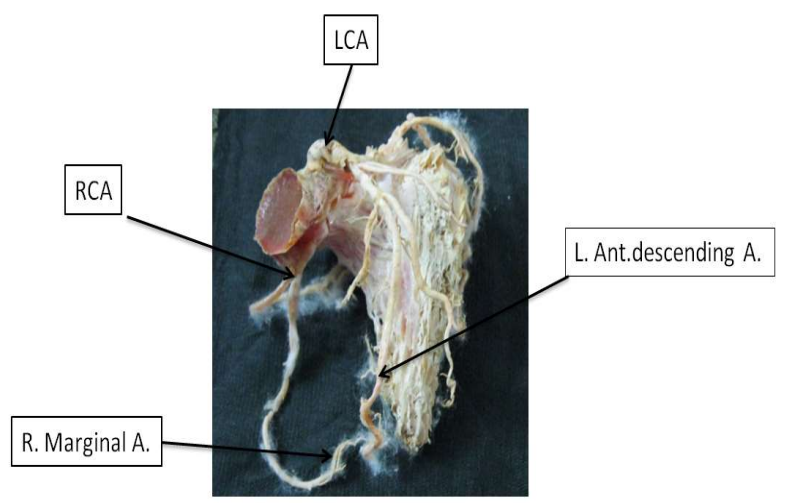

the anterior aortic and left posterior aortic sinus respectively in all the specimens similar to the Abuchaim DC [5], Bhimalli S [6], Kalpana R. [2], the right coronary ostium was 
found in the anterior aortic sinus and the left coronary ostium was found in the left posterior aortic sinus in all the specimens studied. According to P.Dharmendra et al. [7], the right coronary ostium was found in the anterior aortic sinus in all the specimens and the left coronary ostium was found in the left posterior aortic sinus in all the specimens except in 1.07 $\%$ of cases left coronary artery was originated from anterior aortic sinus.

According to Kalpana R [2], Bhimalli S [6], Ballesteros LE [8], Gray's [9] and Dr Devi Reddy Krishna Reddy et al [10] right coronary artery terminated at the crux or beyond crux of heart in $82 \%, 74.99 \%, 89.2 \%, 60 \%$ and $55 \%$ of specimens respectively. In present study right coronary artery terminated at the crux or beyond crux of heart in $70 \%$ of the specimens.

According to Kalpana R [2], Bhimalli S [6] and Gray's [9] right coronary artery terminated at the right border in $7 \%, 16.6 \%$ and $10 \%$ of specimens respectively. According to Dr Devi Reddy Krishna Reddy et al [10] right coronary artery terminated before the right border in $15 \%$ of specimens. In present study right coronary artery terminated at the right border in $10 \%$ of the specimens.

According to Kalpana R [2], Bhimalli S [6], Ballesteros LE [8], Gray's [9] and Dr Devi Reddy Krishna Reddy et al [10] right coronary artery terminated between right border and crux in 3 $\%, 8.33 \%, 8.6 \%, 10 \%$ and $30 \%$ of specimens respectively. In present study right coronary

Table 2: Showing comparison of level of termination of right coronary artery.

\begin{tabular}{|l|c|c|c|c|}
\hline \multirow{2}{*}{ Authors } & Normal & \multicolumn{3}{c|}{ Variations } \\
\cline { 2 - 5 } & $\begin{array}{c}\text { Crux or Beyond crux } \\
\text { of heart }\end{array}$ & $\begin{array}{c}\text { At or before the } \\
\text { right border }\end{array}$ & $\begin{array}{c}\text { Between right } \\
\text { border and crux }\end{array}$ & $\begin{array}{c}\text { At the left border (After } \\
\text { traversing entire AV groove) }\end{array}$ \\
\hline Kalpana R (2003) [2] & $82 \%$ & $7 \%$ & $3 \%$ & $8 \%$ \\
\hline Bhimalli S (2011) [6] & $74.99 \%$ & $16.60 \%$ & $8.33 \%$ & - \\
\hline Ballesteros LE(2011) [8] & $89.20 \%$ & - & $8.60 \%$ & $2.20 \%$ \\
\hline Gray's [9] & $60 \%$ & $10 \%$ & $10 \%$ & $20 \%$ \\
\hline Dr Devi Reddy Krishna Reddy et al (2017) [10] & $55 \%$ & $15 \%$ & $30 \%$ & - \\
\hline Present study & $70 \%$ & $10 \%$ & $3.33 \%$ & $16.66 \%$ \\
\hline
\end{tabular}

Table 3: Showing comparison of level of termination of right marginal artery.

\begin{tabular}{|c|c|c|}
\hline Authors & At the apex & Near to the apex \\
\hline Baroldi and Scomazzoni (1967) [9] & $93 \%$ & $7 \%$ \\
\hline Hossain A (2009) [11] & $27.77 \%$ & $72.22 \%$ \\
\hline Present study & $76.66 \%$ & $23.33 \%$ \\
\hline
\end{tabular}


Table 4: Showing comparison of source of origin of sinu-atrial nodal artery (SANA).

\begin{tabular}{|l|c|c|c|c|}
\hline \multicolumn{1}{|c|}{ Authors } & RCA & LCA & Both & $\begin{array}{c}\text { Directly } \\
\text { from aorta }\end{array}$ \\
\hline Baroldi \& Scomazzoni (1956) [9] & $51 \%$ & $41 \%$ & $8 \%$ & - \\
\hline James TN (1958) [12] & $61 \%$ & $39 \%$ & - & - \\
\hline Kalpana R (2003) [2] & $56 \%$ & $35 \%$ & $8 \%$ & $1 \%$ \\
\hline Ballesteros LE (2011) [8] & $60.60 \%$ & $34.90 \%$ & $4.50 \%$ & \\
\hline Dr Devi Reddy Krishna Reddy et al (2017) [10] & $80 \%$ & $20 \%$ & - & - \\
\hline Gray's [9] & $65 \%$ & $35 \%$ & - & - \\
\hline Present Study & $83.33 \%$ & $16.66 \%$ & - & - \\
\hline
\end{tabular}

\section{CONCLUSION}

The advances made in coronary artery bypass surgeries and modern methods of myocardial revascularization needs a complete knowledge of the normal anatomy of coronary arteries with its variations.

In present study right dominance was most common (90\%). SA nodal artery was a branch of right coronary artery in $83.33 \%$ of hearts.

In present study casts of coronary arteries are made by corrosive cast technique using epoxy resin. Casts prepared by this method provide a new three dimensional perspective of normal anatomy of coronary arteries and their variations. It has proven safer, more economical \& better method for study and preservation of vascular pattern of heart.

\section{ACKNOWLEDGEMENTS}

I am very grateful to Dr. (Mrs.) C. A. Pensi, M.S. (Anatomy), M.S. (Obst. \& Gynec.), Ex.Professor \& Head, Department of Anatomy, B.J.Medical College, Ahmedabad, for her keen interest, timely advice and constant support, which helped me to complete this study. Without her guidance $\&$ suggestion this study could have never been completed.

\section{ABBREVIATIONS}

AP - Antero-posterior

AV - Atrio-ventricular

IV - Interventricular

LCA - Left coronary artery

PA - Postero-anterior

RCA - Right coronary artery

SA Node - Sinu-atrial node

SANA - Sinu-atrial nodal artery

\section{Conflicts of Interests: None}

\section{REFERENCES}

[1]. Allwork SP. The applied anatomy of the arterial blood supply to the heart in man. J. Anat. Great Britain 1987;153:1-16.

[2]. Kalpana, R. A study on principal branches of coronary arteries in humans. J Anat. Soc. India 2003;52(2):137-140.

[3]. Olry RJ Short history of vascular injections, with special reference to the heart vessels. Int Soc Plastination 1998;13(1):7-11.

[4]. Aultman A, Blythe J, Sowder H, Trotter R, Raoof A. Enhancing the value of organ silicone casts in human gross anatomy education. Journal of the international society for plastination 2003;18:9-13.

[5]. Abuchaim DC, Spera CA, Faraco DL, Ribas Filho JM, Malafaia $O$. Coronary dominance patterns in the human heart investigated by corrosion casting. Rev Bras Cir Cardiovasc 2009;24(4):514-518.

[6]. Bhimalli S, Dixit D, Siddibhavi M, Shirol VS. A study of variations in coronary arterial system in cadaveric human heart. World journal of science and technology 2011; 1(5): 30-35.

[7]. P.Dharmendra et al Clinically significant anatomical variations of the left coronary artery in human cadaveric hearts. Int j cur res rev, June 2013; 5(12): p. $39-44$

[8]. Ballesteros LE, Ramirez LM, Quintero ID. Right coronary artery anatomy: anatomical and morphometric analysis. Rev Bras Cir Cardiovasc 2011; 26(2): 230-7.

[9]. Standring S, Gray's Anatomy, 40 ${ }^{\text {th }}$ Edition. London: Harcourt Publishers, Elseveir Churchill Livingstone, 2008; Chapter:56 Heart and great vessels

[10]. Dr Devi Reddy Krishna Reddy et al. A Study of Branching Pattern and Distribution of Coronary Arteries in Adult Human Heart. Journal of medical science and clinical research(JMSCR); Volume 05 Issue 1 December 2017; p. 31603-31613

[11]. Hossain A, Ara A, Ara S. Study of right marginal artery in post mortem hearts of adult Bangladeshi people Cardiovasc. j. 2009; 1(2): 165-168.

[12]. James TN, Burch GE. The Atrial Coronary Arteries in Man. Circulation Jan 1958; 17: 90-98.

How to cite this article: Sneha. V. Kumar, Bhavanaben K. Damor. A STUDY OF BRANCHING PATTERN OF RIGHT CORONARY ARTERY IN HUMAN HEARTS BY CORROSIVE CAST METHOD. Int J Anat Res 2020;8(1.2):7283-7287. DOI: 10.16965/ijar.2019.354 